\title{
Introduction to the JOCN Special Issue on Machine Learning and Data Analytics for Optical Communications and Networking
}

\author{
Tornatore, Massimo; Birk, Martin; Lau, Alan Pak Tao; Zhang, Qiong; Zibar, Darko
}

Published in:

Journal of Optical Communications and Networking

Link to article, DOI:

10.1364/JOCN.10.000ML1

Publication date:

2018

Document Version

Publisher's PDF, also known as Version of record

Link back to DTU Orbit

Citation (APA):

Tornatore, M., Birk, M., Lau, A. P. T., Zhang, Q., \& Zibar, D. (2018). Introduction to the JOCN Special Issue on Machine Learning and Data Analytics for Optical Communications and Networking. Journal of Optical Communications and Networking, 10(10). https://doi.org/10.1364/JOCN.10.000ML1

\section{General rights}

Copyright and moral rights for the publications made accessible in the public portal are retained by the authors and/or other copyright owners and it is a condition of accessing publications that users recognise and abide by the legal requirements associated with these rights.

- Users may download and print one copy of any publication from the public portal for the purpose of private study or research.

- You may not further distribute the material or use it for any profit-making activity or commercial gain

- You may freely distribute the URL identifying the publication in the public portal 


\title{
Introduction to the JOCN Special Issue on Machine Learning and Data Analytics for Optical Communications and Networking
}

\author{
Massimo Tornatore, Martin Birk, Alan Pak Tao Lau, Qiong Zhang, and Darko Zibar
}

\begin{abstract}
This Special Issue contains a collection of outstanding papers covering several applications of machine learning in optical communications and networking, including: resource management in elastic optical networks, datacenters and ROADM-based networks; noise and signalquality estimation; and traffic prediction. We provide a brief overview of the current state of machine learning in optical networks, followed by a categorization of the eleven papers in this special issue.
\end{abstract}

This special issue of JOCN focuses on new applications of Machine Learning (ML) and data analytics for the design and operation of next-generation optical communication systems and networks. The increasing complexity of networks combined with the growing desirability for dynamic services and adaptable networks have led to a need for new techniques to automate and optimize network operation. ML allows the inference of useful network characteristics that cannot be easily or directly measured. This offers operational advantages by allowing the network to 'draw conclusions' and react autonomously.

There is a range of applications in optical networks that can take advantage of ML. For example, recent studies have shown how ML may enable pro-active and autonomous virtual topology reconfiguration based on network state, or may provide rapid and accurate estimation of the quality of transmission of a new connection. In general, several benefits, deriving from the automation of network management tasks traditionally performed with human intervention, have been already demonstrated.

Consequently, it was appropriate for JOCN to solicit papers for this special issue on ML to stimulate a more thorough assessment of these benefits. The call for papers

Manuscript received September 17, 2018; published October 1, 2018 (Doc. ID 346227).

Massimo Tornatore (e-mail: massimo.tornatore@polimi.it) is with Politecnico di Milano, Italy.

Martin Birk is with AT\&T, Dallas, Texas 75202, USA.

Alan Pak Tao Lau is with The Hong Kong Polytechnic University, Hong Kong SAR, China.

Qiong Zhang is with Fujitsu Laboratories of America, Inc., Sunnyvale, California 94085, USA.

Darko Zibar is with Technical University of Denmark (DTU), Denmark. https://doi.org/10.1364/JOCN.10.000ML1 attracted manuscripts with topics ranging from pure physical-layer analysis to network optimization. Some of the contributions present a clear industrial footprint, while others explore more theoretic aspects, enriching the special issue with a nice blend of perspectives.

The issue includes three invited papers. One is a tutorial ("Machine Learning for Network Automation: Overview, Architecture, and Applications") that provides a comprehensive introduction to the field. Two others are invited contributions from industry, shedding light on traffic prediction and optical-path performance prediction ("Two Use Cases of Machine Learning for SDN-Enabled IP/Optical Networks: Traffic Matrix Prediction and Optical Path Performance Prediction"), and on anomaly detection in the optical layer ("Using Machine Learning in Communication Networks").

The purpose of the special issue is to stimulate discussion on possible new and unexplored applications of ML, and indeed most of the accepted contributed papers cover completely novel fields of application, opening new and interesting fields of research. Three of them describe the application of ML for cognitive resource management in various domains such as intra- and inter-datacenter networks ("Machine Learning-Based Prediction for Resource (Re)allocation in Optical Data Center Networks" and "Deep-Learning-Assisted Network Orchestration for On-Demand and Cost-Effective vNF Service Chaining in Inter-DC Elastic Optical Networks," respectively), and ROADM systems ("Deep-Neural-Network-Based Wavelength Selection and Switching in ROADM Systems"). One paper explores energy conservation ("Using Machine Learning to Balance Energy Cost and Emissions in Optical Networks"). Three papers address improving the estimation of critical physical-layer parameters ("Machine Learning Based Linear and Nonlinear Noise Estimation", "Simple Learning Method to Guarantee Operational Range of Optical Monitors" and "Machine Learning Models for Estimating Quality of Transmission in DWDM Networks"). Additionally, the application of ML to next-generation optical access systems is presented in one paper ("Auto-Tuning PID Distributed Power Control for Next Generation Passive Optical Networks"). 
We hope that you will find this special issue informative and inspiring for your future research.

\section{Guest Editors}

Massimo Tornatore, Politecnico di Milano, Italy

Lead Guest Editor

Martin Birk

AT\&T, United States
Alan Pak Tao Lau

The Hong Kong Polytechnic University, Hong Kong SAR, China

Qiong Zhang

Fujitsu Laboratories of America, Inc., United States

Darko Zibar

Technical University of Denmark (DTU), Denmark

Jane M. Simmons

Editor-in-Chief 